\title{
"We are a Bit Blind About it": A Qualitative Analysis of Climate Change-Related Perceptions and Communication Across South African Communities
}

\author{
Schäfer, Mike S ; Siegen, Dario ; Mahl, Daniela
}

\begin{abstract}
Climate change-related perceptions and communication are important factors influencing people's support for climate change policies and individual behavior. Since research on both climate change-related perceptions and communication is biased towards Western countries and standardized research methodologies, this paper investigates perceptions across South African communities using a deductive-inductive qualitative approach. 20 individuals in three communities of a South African town were interviewed about their climate change-related perceptions and communication. Results show that for individual concepts of climate change, interviewees' perceptions differed across the communities: higher educated communities had more differentiated and diverse conceptions of causes and consequences of climate change and potential countermeasures. Most interviewees, across the communities, stressed that they considered climate change as an important problem, although other social problems seemed more pressing. Interestingly, all three communities most frequently encounter the issue of climate change through new and traditional mass media, but their self-assessed knowledge about it varies widely.
\end{abstract}

DOI: https://doi.org/10.1080/17524032.2020.1736116

Posted at the Zurich Open Repository and Archive, University of Zurich

ZORA URL: https://doi.org/10.5167/uzh-199081

Journal Article

Accepted Version

Originally published at:

Schäfer, Mike S; Siegen, Dario; Mahl, Daniela (2020). "We are a Bit Blind About it”: A Qualitative Analysis of Climate Change-Related Perceptions and Communication Across South African Communities. Environmental Communication, 14(6):802-815.

DOI: https://doi.org/10.1080/17524032.2020.1736116 


\title{
"We are a bit blind about it": A qualitative analysis of climate change-related perceptions and communication across South African communities
}

\author{
Accepted for publication in Environmental Communication
}

\begin{abstract}
Authors:
(Corresponding author) Daniela Mahl, University of Hamburg, Institute for Journalism and Communication Studies, Allende-Platz 1, 20146 Hamburg, Germany, daniela.mahl@unihamburg.de, Tel. +49 $4042838-9482$

Lars Guenther, University of Hamburg, Institute for Journalism and Communication Studies, Grindelberg 7, 20144 Hamburg, Germany, lars.guenther@ uni-hamburg.de, Tel. +49 4042383 7775

Mike S. Schäfer, University of Zurich, IKMZ - Department of Communication and Media Research, Andreasstrasse 15, CH-8050 Zurich, m.schaefer@ikmz.uzh.ch, Tel. +41 4463520 $\underline{80}$

Corlia Meyer, Stellenbosch University, Centre for Research on Evaluation, Science and Technology, Stellenbosch, 8001, South Africa, corliameyer@sun.ac.za, Tel. +27 8089954 Dario Siegen, University of Zurich, IKMZ - Department of Communication and Media Research, Andreasstrasse 15, CH-8050 Zurich, dario.siegen@ hotmail.com, Tel. +41 7642456 52
\end{abstract}

\section{Acknowledgements}

This research is based on research supported by the South African Research Chairs Initiative of the Department of Science and Technology (DST) and National Research Foundation (NRF) of South Africa. Any opinion, finding and conclusion or recommendation expressed in this material is that of the authors and the NRF does not accept any liability in this regard. The authors thank Mr L Magenuka for his assistance with the interviews and Mr PM Sibula for translating and transcribing interviews from isiXhosa to English. Thank you also to Ms D Duvenage for transcribing all other interviews. Additional thanks go to Prof H Kotzé for his insightful advice and comments and Prof $\mathrm{P}$ Weingart for his conceptual help. 


\begin{abstract}
Climate change-related perceptions and communication are important factors influencing people's support for climate change policies and individual behavior. Since research on both climate change-related perceptions and communication is biased towards Western countries and standardized research methodologies, this paper investigates perceptions across South African communities using a deductive-inductive qualitative approach. 20 individuals in three communities of a South African town were interviewed about their climate change-related perceptions and communication. Results show that for individual concepts of climate change, interviewees' perceptions differed across the communities: higher educated communities had more differentiated and diverse conceptions of causes and consequences of climate change and potential countermeasures. Most interviewees, across the communities, stressed that they considered climate change as an important problem, although other social problems seemed more pressing. Interestingly, all three communities most frequently encounter the issue of climate change through new and traditional mass media, but their self-assessed knowledge about it varies widely.
\end{abstract}

\title{
Keywords:
}

Climate change, perceptions of climate change, media use and information sources, South Africa, qualitative interviews, Global South 


\section{"We are a bit blind about it": A qualitative analysis of climate change-related perceptions and communication across South African communities}

\section{Introduction}

The issue of climate change has dominated the environmental discourse since the $1980 \mathrm{~s}$ (Babugura, 2010). It is seen by many as one of the most threatening problems worldwide, and addressing it has become a global priority. Public awareness, understanding, and attitudes towards climate change are important factors in addressing climate change, as they influence people's support for climate change-related policies (Lorenzoni \& Pidgeon, 2006), as well as their own climate change-related behavior (Leiserowitz, 2007; Wolf \& Moser, 2011).

Consequently, public perceptions of climate change have been studied extensively over the last three decades (for overview see Lee, Markowitz, Howe, Ko, \& Leiserowitz, 2015; Leiserowitz, 2007; O'Connor, Bard, \& Fisher, 1999). Research on different countries - mainly on the US and Western Europe, more rarely on parts of Africa, Asia, and Latin America (cf. Schäfer \& Schlichting, 2014) - has shown that climate change has entered public debate and awareness (e.g., Lorenzoni \& Pidgeon, 2006; Schmidt, Ivanova, \& Schäfer, 2013). This research has also exhibited that climate change is a complex issue; difficult to understand for the broader public and, for many, hard to relate to their daily lives (Moser, 2010).

As a result, and despite of an overwhelming scientific consensus on anthropogenic climate change (Intergovernmental Panel on Climate Change (IPCC), 2018), many individuals still harbor misconceptions (Reynolds, Bostrom, Read, \& Morgan, 2010; Weber \& Stern, 2011). Generally, individual perceptions of climate change are based on complex social, moral, psychological, institutional, and cultural processes which influence how people perceive climate change, potential solutions to it, as well as their own attitudes and behavior towards it (Leiserowitz, 2005).

Climate change is an unobtrusive issue, complex, and not directly and easily perceivable for many people (Moser, 2010; Schäfer, 2015). However, research on climate change communication has shown that individual perceptions of climate change are strongly influenced by how the public, media and other sources of information portray the issue (for overviews see, e.g., Brevini \& Lewis, 2018). Accordingly, these sources of information are "important arenas and important agents in the production, reproduction, and transformation of the meaning" of climate change (Carvalho, 2010, p. 172).

As a result, research on climate change perceptions and climate change communication has mushroomed in past years (for overviews see Leiserowitz, Maibach, \& Roser-Renouf, 
2009; Nisbet et al., 2018; Wolf \& Moser, 2011). However, this research has a number of shortcomings, two of which are particularly relevant for this study: First, scholarship is strongly biased towards "Western", industrialized countries, while countries from the "Global South"1 have received far less scholarly attention, with European and North American countries (Leiserowitz et al., 2009) receiving most scholarly attention and African, Asian and Latin American nations receiving little interest (Leiserowitz, 2007; Schäfer \& Schlichting, 2014), even though climate change impacts there are often more pronounced than elsewhere (IPCC, 2018). Second, scholarship is mostly based on standardized methods, often representative quantitative surveys (Lorenzoni \& Pidgeon, 2006; Wolf \& Moser, 2011), which offer insights into general patterns of climate change perceptions and communication, but which are less suitable for detailed, close descriptions of individual perceptions of climate change and the related use of media and other information sources (Whitmarsh, 2009). For such questions, explorative, qualitative studies are more appropriate.

This study tackles both shortcomings. We provide an in-depth, qualitative analysis of climate change perceptions and communication in a country from the Global South: South Africa.

\section{Conceptual framework}

\section{Analyzing climate change-related perceptions and communication in South Africa}

Africa is highly vulnerable to climate change, due to its low adaptive capacity, its sensitivity to predicted changes (Steynor \& Pasquini, 2019), and because the majority of its population lives in elevated poverty (IPCC, 2007). For some scholars, Africa is the continent most vulnerable to climate change (Selormey, Dome, Osse, \& Logan, 2019). Many climate models predict an increase in the occurrence of extreme weather events in numerous areas across Africa (Thomas, Twyman, Osbahr, \& Hewitson, 2007). Sub-Saharan Africa is amongst the most vulnerable regions and the IPCC predicts that future warming is expected to be above the global average (Bryan, Deressa, Gbetibouo, \& Ringler, 2009).

Consequences of climate change are already present in South Africa - such as rising mean temperatures and decreasing mean rainfall (Maponya, Mpandeli, \& Oduniyi, 2013) - and these changes are predicted to become more intense in the future (DARA, 2012). South Africa also plays a special role in global climate politics. It is part of the BASIC (Brazil, South Africa,

\footnotetext{
${ }^{1}$ Global South, broadly defined, refers to countries in Latin America, Asia, Africa, and Oceania. Hence, it refers to regions "outside Europe and North America, mostly [...] low-income and often politically or culturally marginalized" (Dados and Connell, 2012, p. 12).
} 
India, and China) negotiation group at the international conferences of the parties to the United Nations Framework Convention on Climate Change (UNFCCC). At the same time, South Africa is Africa's biggest greenhouse gas (GHG) emitter and regularly ranks among the planet's biggest 20 GHG emitting nations (WRI, 2014).

Still, only few studies have analyzed the public perception and communication of climate change in South Africa. These studies overwhelmingly employ quantitative, standardized research methods to assess media coverage (e.g., Schmidt et al., 2013), public perceptions of climate change (e.g. Seager, 2008) or perceptions of specific groups such as farmers (e.g., Bryan et al., 2009). Qualitative analyses of individual perceptions and climate change-related media and information use in South Africa are scarce (for exceptions, see the research programme Africa Talks Climate; Burton et al., 2010, for findings across ten African nations; Neville, 2010, for South Africa).

\section{Analyzing climate change perceptions, climate change communication and their drivers}

Studies dealing with perceptions of climate change are usually interested into people's concerns about and attitudes towards climate change. They also try to determine to what degree influencing factors such as sociodemographic variables, knowledge, and climate changerelated media use have an impact on perceptions, as well as on how perceptions translate into related behavior (Lorenzoni \& Pidgeon, 2006). In many cases, data have been analyzed across time and countries (Wolf \& Moser, 2011).

Surveys show that in many countries, people are concerned about climate change, but see the topic as secondary in relation to other social issues (Lorenzoni \& Pidgeon, 2006) and as more a distant threat (Wolf \& Moser, 2011). South Africans seem to see the issue as even less serious than other countries (see also Brechin \& Bhandari, 2011; Ray \& Pugliese, 2011). This is surprising, as research has emphasized that across six African countries, South Africa included, climate change seems more psychologically close in Africa compared to developed countries (Steynor \& Pasquini, 2019). This aligns with findings from a study across ten African countries, South Africa included: climate change is already determining people's lives and as such not seen as an abstract issue (Burton et al., 2010). Concern about climate change has risen in recent years. In 2007/2008, 21\% of South Africans declared climate change to be a "very" or "somewhat" serious threat, which rose to $28 \%$ in 2010 (Pugliese \& Ray, 2011). Compared to other countries, however, many South Africans are still under-informed: over $50 \%$ of South Africans have not heard of climate change and only $24 \%$ realize its negative implications (Selormey et al., 2019). Even if people have an idea of what climate change is, the concept is 
often not well understood (Burton et al., 2010). Presumably as a consequence, on a global level, South Africans are less concerned about the issue. Those that are aware of the issue and recognize South Africa's contribution to climate change nevertheless express reluctance to change their lifestyle; they rather address industry and politics to take action (Neville, 2010).

Individual conceptions of climate change seem to differ significantly from scientific understandings (Lorenzoni \& Pidgeon, 2006). For South Africa, studies thus far seem inconclusive on central perception-related factors, such as do people believe climate change is real, what do they think causes it, and what can be done about it. This may partly be due to the limited amount of scholarship on the South African case, but also due to the largely quantitative nature of this research.

To better understand perceptions of climate change in South Africa, the study at hands asks, firstly, What are South Africans' perceptions of climate change? (RQ1). To assess their subjective concepts of climate change, the study explores whether interviewees agree with core assumptions of the IPCC (IPCC, 2014; Brüggemann \& Engesser, 2017), i.e. about the existence of global warming, its anthropogeneity, its impacts, and potential countermeasures. In addition, it focuses on people's attitudes towards climate change, asking whether they see it as an important problem for themselves, their immediate context and South Africa more generally, and how concerned they are about it.

Perceptions people have about climate change can be shaped by communication (Metag, Füchslin, \& Schäfer, 2017). International research has demonstrated that media presentations have considerable influence on people's perceptions of climate change as it is the most important source of information for many people (e.g. Stamm, Clark, \& Eblacas, 2000), which is likely also true for South Africa (Neville, 2010). The chosen sources influence perceptions of climate change, in some cases even behavioral intentions or behavior (Metag et al., 2017; Taddicken, 2013). Hence, it is important to understand the channels through which people receive climate change-related information (White, 2011) and if information sources and media use influence perceptions. Research across ten African countries indicates that journalistic training on reporting climate change, intense media coverage, and public awareness campaigns are lacking in these countries, especially in rural parts (Burton et al., 2010). In addition, recent studies show that although coverage of climate change is increasing in the Global South, the quantity and quality of reporting is insufficient and the necessary information is not made available to those affected (Guenther, Weingart, \& Joubert, 2018; Painter, 2014; Shanahan, 2009). Moreover, in some countries of the Global South, such as India or African countries, climate change is interpreted from a (post)colonial perspective (Billett, 2010; Rao \& 
Wasserman, 2007). However, data on South Africans' media and information use is scarce. Therefore, RQ2 asks: How do South Africans use media and other sources of information on climate change? Thus, this study assesses where South Africans get information about climate change, for example from the media or other information sources, such as NGOs, political or religious authorities, or through interpersonal communication with friends, acquaintances or colleagues at work. In addition, this study will examine how South Africans perceive and describe this information, what they take from it, and whether they feel informed as a result.

Perceptions of climate change are specific to context and location due to the heterogeneity of variables that affect them (Wolf \& Moser, 2011). South Africa comprises of various communities with different cultural backgrounds, beliefs, norms, and values (Babugura, 2010). Therefore, it is rather unlikely to make generalizations across the entire South African population for climate change perceptions and communication. Previous research in South Africa has indicated that significant variables in the prediction of awareness and adaptation of climate change include, among others, gender, age, and education (Babugura, 2010; Mandleni \& Anim, 2011).

Studies have shown that gender affects perceptions of climate change risks, with females being more concerned about it (Wolf \& Moser, 2011). Furthermore, younger South African individuals generally estimated their knowledge to be higher than elder respondents (Seager, 2008). Factors such as socioeconomic status, education, and locations (urban vs. rural) have also been named to have an impact on perceptions of climate change (Babugura, 2010; Crona, Wutich, Brewis, \& Gartin, 2013).

Globally, it was found that people have a limited understanding of the human contribution to climate change (Lorenzoni \& Pidgeon, 2006). In South Africa, the public also seem to have little knowledge about the causes of climate change (Pugliese \& Ray, 2011). The majority does not associate weather and environmental changes with global causes of climate change. Rather, many South Africans think that these changes are due to local environmental degradation, e.g. deforestation, which in turn is responsible for droughts (Burton et al., 2010). Regarding locations, individuals living in urban areas might be further distant from the environment (Wolf \& Moser, 2011), which might also potentially affect their perceptions of climate change. It has also been shown repeatedly that household income influences how individuals see climate change. Those with a lower income are less aware of and show less concern for climate change (Metag et al., 2017; Murphy \& Tinga, 2019).

The variables listed here - gender, age, household income, education, place of living - likely do not impact perceptions of climate change in isolation. They represent social 
positions and milieus which form worldviews that influence interpretations of and responses to climate change information (Wolf \& Moser, 2011). Based on this, the present paper employs a qualitative study to assess climate change perceptions and the related use of media and information sources in South African communities.

\section{Method}

\section{Study design, selection of communities and interviewees}

Within South Africa, the Western Cape is particularly interesting. It is vulnerable to climate change in a number of ways; increased air temperature, less precipitation, and higher sea levels are predicted and may lead to more extreme droughts, increased saltwater intrusion, flooding, coastal erosion, and less biodiversity (Midgley et al., 2005). Stellenbosch, a town in the Western Cape, has been affected by the ongoing drought and the resulting water crisis since 2015 and is characterized by its heterogeneous population with regards to the variables that have been shown to be relevant for climate change perceptions and communication. Therefore, this study focused on this region for the analysis.

Twenty semi-structured, in-depth interviews were conducted in six neighborhoods of Stellenbosch between October 2017 and January 2018. These neighborhoods were classified into three overarching communities: urban (Stellenbosch central, Rozendal, Onder Papegaaiberg; $n=7$ ), urban low income (Cloetesville, Kayamandi; $n=11$ ) and rural (Pniel; $n$ $=2$ ). The communities were chosen in order to present Stellenbosch's demography and to enable cross-community comparisons. This study combined a "most different" comparative design, which generally aims to determine similarities between very different objects (cf. Przeworski \& Teune, 1970, 39ff.), with a "most similar" comparison, which aims to elucidate differences between similar cases. Using theoretical sampling with voluntary interviewees, in each community importance was attached to a balanced distribution of age, gender, home language, socioeconomic status, and education in order to represent important social categories and the diversity of Stellenbosch. Table 1 gives an overview of the socio-demographic information of the interviewees in each community. The interviewees were recruited with the assistance of local businesses, farm owners, NGOs, school representatives, and members of the Stellenbosch Municipality. 
Table 1. Socio-demographic overview

\begin{tabular}{|c|c|c|c|c|c|c|}
\hline$N r$. & Age & Gender & Home language & Population group & Education & Income \\
\hline \multicolumn{7}{|c|}{$\operatorname{Urban}(n=7)$} \\
\hline \multicolumn{7}{|c|}{ Stellenbosch central $(n=2)$} \\
\hline 13 & 22 & male & English & white & high & moderate \\
\hline 19 & 20 & male & English & white & high & low \\
\hline \multicolumn{7}{|c|}{ Rozendal $(n=3)$} \\
\hline 1 & 60 & male & English & white & high & high \\
\hline 3 & 43 & male & Afrikaans & white & high & high \\
\hline 5 & 31 & female & Afrikaans & white & high & high \\
\hline \multicolumn{7}{|c|}{ Onder Papegaaiberg $(n=2)$} \\
\hline 2 & 65 & female & Afrikaans/English & white & moderate & - \\
\hline 4 & 39 & female & Afrikaans & white & high & high \\
\hline
\end{tabular}

Urban low income $(n=11)$

Cloetesville $(n=3)$

\begin{tabular}{|c|c|c|c|c|c|c|}
\hline 6 & 79 & female & Afrikaans & coloured $^{\mathrm{a}}$ & low & low \\
\hline 7 & 44 & female & Afrikaans & coloured & moderate & low \\
\hline 8 & 61 & male & Afrikaans & coloured & moderate & moderate \\
\hline \multicolumn{7}{|c|}{ Kayamandi $(n=8)$} \\
\hline 10 & 26 & female & IsiXhosa & black & moderate & low \\
\hline 11 & 19 & female & IsiXhosa & black & moderate & low \\
\hline 12 & 27 & female & isiXhosa & black & moderate & - \\
\hline 14 & 26 & male & isiXhosa & black & moderate & low \\
\hline 15 & 40 & male & isiXhosa & black & moderate & low \\
\hline 16 & 27 & female & isiXhosa & black & high & - \\
\hline 17 & 23 & female & isiXhosa & black & moderate & - \\
\hline 18 & 33 & male & isiXhosa & black & high & moderate \\
\hline
\end{tabular}

Rural $(n=2)$

Pniel $(n=2)$

$\begin{array}{lllllll}9 & 24 & \text { female } & \text { Afrikaans } & \text { coloured } & \text { high } & \text { moderate } \\ 20 & 72 & \text { male } & \text { English } & \text { coloured } & \text { moderate } & \text { moderate }\end{array}$

Notes: Low education $=$ no schooling or primary school; moderate education $=$ high school until matric; high education $=$ tertiary education. Low income $=\mathrm{R}<7.500$; moderate income $=\mathrm{R}$ 7.500 $-15.000 ;$ high income $=>15.000$

${ }^{\mathrm{a}}$ Coloured is a term in South Africa to describe descendants of mixed ethnic heritage 


\section{Data acquisition via qualitative interviews}

Qualitative interviews were conducted by three trained individuals, two of the authors and one student, using a semi-structured interview guideline. Before conducting the interviews, the three interviewers trained together and conducted pre-tests. The aim was to ensure that all interviewers conduct the interview following the guideline, respond similarly to questions or lack of knowledge, and that they enable respondents to get comfortable. Interviews were carried out in three of the eleven official South African languages spoken in the Western Cape: Afrikaans (40\%), isiXhosa (40\%), and English (20\%). The semi-structured format enabled follow-up questions based on answers (Ballantyne \& Oelofse, 1999). Interviews were conducted where respondents felt most comfortable, either at their home, work or in a public place such as a cafe. In order to get the respondents used to the interview situation, they were first asked to tell something about themselves. Interviewees themselves determined the duration and the succession of topics of each interview individually. On average, interviews lasted approximately half an hour (in minutes: $M=27.1 ; S D=10.4$ ).

A number of qualitative and quantitative preliminary studies were taken into account for the development of the interview guideline (Abramson \& Inglehart, 1995; Babugura, 2010; Bakuwa, 2015; Brechin \& Bhandari, 2011; Guenther, Weingart, \& Meyer, 2018; HSRC, 2007; Neville, 2010; Whitmarsh, 2009). The interview began with the participants being asked to talk about themselves. Subsequently, interviewees were asked to name major problems faced by South Africa, their community and themselves. Interviewees were able to choose from several examples: HIV/AIDS, unemployment, racism/xenophobia, education, poverty, or climate change. Afterwards, the interviewees were asked whether they had ever heard of climate change. Interviewees' subjective concepts of climate change were determined by the following questions: Do you believe climate change is real? What do you think causes it? What are its impacts, and are you personally affected? What can be done about it, and who could or should do this? Attitudes towards climate change were assessed by asking whether climate change is an important problem, for the associations interviewees have about it, and their feelings about it. In addition, interviewees were asked about their information sources, i.e. about where have they heard about climate change, and what their sources were and in how well they felt informed.

All interviews were recorded with interviewees' consent, transcribed verbatim and, where necessary, translated into English. Interview transcripts were anonymized to preserve confidentiality. 


\section{Data analysis: Qualitative content analysis}

Interview transcripts were coded and evaluated by two of the authors using qualitative content analysis (Mayring, 2015). This approach emphasizes an iterative process of interpreting, paraphrasing, and aggregating the material under analysis. In accordance with the approach, some coding categories were deductively determined before the analysis (e.g., impacts of climate change), but coders also had the option to change or adapt these codes during analysis, as well as to add new ones inductively (e.g., level of elaboration). The following interview excerpt illustrates the coding procedure:

[I] 's scary sometimes when you see things like these. So there comes a time of being afraid sometimes, just because what you are looking at as you see there is poverty already but the more climate change, the more poverty goes up. [...] I will speak about myself as a person working in the hospitality industry. [...] So in places like hotels they use a lot of water because here in Cape Town. Here in Cape Town water is scarce. (Interviewee No. 18)

At the beginning of the quote, the interviewee explains that climate change sometimes frightens him (e.g., "it's scary sometimes"). These statements were used for the question What are your feelings about it? (Attitudes towards climate change). Furthermore, the statements "the more climate change, the more poverty" and "water is scarce" were used to answer the question What are its impacts, and are you personally affected? (Subjective concepts of climate change). Additionally, we have not only coded statements that directly address our research questions, but also statements that provide information on how climate change indirectly affects people's lives, such as that the interviewee works in the hospitality industry. If the interviewees' answers were inconsistent or contradictory, this was noted in the codebook. It is also important to note that four interviewees did not know or had never heard of climate change. This information was also recorded in the codebook so that the responses of these interviewees could be evaluated correctly.

\section{Results}

Perceptions of climate change across communities (RQ1)

To assess interviewees' subjective concepts of climate change, they were first asked whether they thought climate change existed. A clear majority of the interviewees were indeed convinced that climate change is real. They said, for example, "of course it's real, it's very real" (No. 2) or "it's true - I see [it] outside" (No. 16). However, one interviewee additionally added that while he believed climate change was real, it also "could be fake" (No. 13). 
When comparing responses across the three communities, however, clear differences emerged. While interviewees of the urban and rural communities were almost unanimously convinced of the existence of climate change, and stated this quite strongly, this was not the case in the urban low income community. Four interviewees from this community could not answer this question, because they had not heard of climate change before. Even after being told what climate change is, what effects it has on people and environment, they were unable to answer the question.

Second, we asked interviewees what they thought the causes of climate change were. Again, the majority emphasized the anthropogenic nature of climate change. Many interviewees indicated, for instance, that it "humanity in general" (No. 13) and "not a certain ethnic group" (No. 2) that is causing climate change. As main causes, they consistently named "gasses we are throwing into the air" (No. 19), even though some of them mixed these causes with more general themes like a "lack of sustainability, cutting down the forests [, and] throwing our waste into the sea" (No. 19).

This was true for all communities - but the degree of elaboration in the responses differed across the communities. Members of the urban community often reflected in a highly differentiated way about possible causes of climate change as well as potential future scenarios. The main causes mentioned by them were deforestation, ocean and air pollution, conventional agriculture, the mining industry, the harmful impact of the fossil fuel and coal industries, and increased GHG emissions. Several of them were able to elaborate on the mechanisms connecting these factors to anthropogenic climate change. Members of this community also stressed that the growing population is particularly detrimental to the climate, as a 65-year-old woman from Onder Papegaaiberg pointed out:

The world is overpopulated [...]. I mean that we are so many people [...] I think that's also got a big effect. (No. 2)

However, many interviewees from this community were also aware that they themselves have a negative influence on the climate, for example by "turning on the washing machine, taking a shower [, the] use [of] plastic products" (No. 19) or "using carbon-based fuels for electricity" (No. 3).

In contrast, interviewees from the urban low income community explained the causes of climate change in a less differentiated way, even though the majority of these interviewees also cited deforestation or what they called "air pollution" - usually, but not in all cases explaining air pollution as the emission of greenhouse gases - as main causes of climate change. When asked whether they believe that they themselves contribute negatively to climate 
change, interviewees responded differently, sometimes in ways that indicate a wrongful understanding of causal mechanisms. Responses varied from "not really" (No. 15) to "I think as someone who is smoking, I do have a contribution" (No. 16). In addition, a 33-year old man from Kayamandi, who believed in anthropogenic climate change, posited, when asked about the causes of climate change, that there are events and circumstances on Earth that man cannot control. Both members of the rural community agreed that "air pollution" - again in the broader sense the term was also used in the urban low income community - was the main cause of climate change. They were both aware of their negative impact on the climate as they drive a car.

When asked about the effects of climate change and whether interviewees were personally affected, the majority of interviewees from all communities stressed that they personally felt the effects of climate change. Interviewees almost unanimously highlighted the severe droughts and increasing water scarcity in the Western Cape region as an example. They stated, for example, that "we run out of water" (No. 12) and that "we have the neighboring countries that actually supply us with water" (No. 15).

Since water is becoming increasingly scarce and therefore more expensive, a new form of consciousness for water and the costs related to climate change has developed. An elderly man from Rozendal explained: "I need to think about every drop" (No. 1). A hotel employee observed that washing napkins of hotel guests was no longer possible due to water shortages, "so we are forced to buy paper serviettes [...]. That costs us a lot financially" (No. 18). In addition to the effects of climate change on nature, a young woman reported on health problems: "I have skin problems. So this thing [...] of climate change doesn't go well with my skin at all" (No.16). Additionally, the communities unanimously reported rising food prices "due to the fact that it becomes more expensive to farm" (No. 5).

Fourth, we asked what countermeasures could be taken to counteract climate change, and who should take them. Almost all interviewees of the urban and the urban low income communities responded similarly to these questions. For example, they called for more "electricity from renewable energy sources such as wind" (No. 13) to cope with the consequences of climate change. In addition, they urged that more information on climate change be communicated to the South African population so that all citizens would understand the phenomenon and tackle its causes and consequences. A young woman from Rozendal said, for instance, that she thinks it would be necessary to spread "a clear message to everybody as to where we stand, what we should do" (No. 5). Other measures to mitigate climate change included recycling, sustainable agriculture, and climate-friendly food production. Additionally, 
interviewees highlighted that every citizen could contribute to combating climate change, for example, "decrease your home waste, do a proper compost heap and do your recycling very effectively" (No. 5), as a woman of the urban community said. However, the majority of both urban communities also emphasized the limited capacity of individuals to take action, and stress the need for systemic change: "Everybody can do a little bit by themselves. But I think systems in general need to change" (No. 5). A 39-year old woman from Onder Papegaaiberg explained why it is not enough to rely on countermeasures by the population: "I don't think people will do radical change[s] unless their lives are threatened" (No. 4). The widespread assumption that people only act when they perceive a personal threat from climate change means that "a government initiative" (No. 1) and politicians are expected to take responsibility and take action against climate change. In addition to politics, science is also held responsible:

I actually think this is a problem that has to be dealt with on a scientific level. We can do little bits as people, but it's more the clever boys that must fix this. (No. 2)

However, the comparison with the rural community again reveals considerable differences. Interviewees of this community were unable to identify any potential countermeasures to combat climate change. A 72-year old man from Pniel said, for example, "something can probably be done. I'm sure of it. I can't say exactly what" (No. 20). However, these interviewees also highlighted that policymakers had a responsibility to act: "I think probably from the government's side if there had to be legislation" (No. 20), ideally from "the highest authority in our country. But that is so messed up, how will they. The one will blame the other" (No. 9).

Apart from assessing interviewees' subjective concepts of climate change, they were asked about their attitudes towards climate change. Most interviewees, across all communities, agreed that climate change is an important and relevant problem that needs to be addressed. At the same time, however, almost all interviewees stressed that there are different personal or societal problems that are more important than climate change, which is why they personally rarely worry about the causes and effects of climate change. A young man from Stellenbosch central described this as follows:

I think it's a pretty serious issue. I know that South Africa is highly reliant on coal. So it's something that is a big issue in South Africa as well and we are a bit blind about it. And me myself, I'm also a bit blind about it. (No. 19)

Interviewees mentioned various other problems they struggle with, even though they consider climate change as a problem. Most interviewees from the urban community regarded political corruption and crime as South Africa's most important problems. A 20-year-old man 
from Stellenbosch central emphasized, the "mismanagement of government funds" and the "extreme loyalty to your party, a blind loyalty" (No. 19). In contrast, the urban low income community identified unemployment and poverty as important issues alongside education and political corruption. A young man from Kayamandi pointed out that many young people are affected by unemployment after graduating. Interviewees from Pniel (rural community) highlighted political corruption, education, and crime as key issues that need to be addressed. They emphasized, for instance, "we just have a lack of information" (No. 9) or that they "have those influences from the outside, you know[,] drugs" (No. 20).

When asked what interviewees associate with climate change, there were no major differences across the communities. All interviewees unanimously associated climate change very closely with visible and tangible causes and effects of it. When asked about their picture of climate change, the majority of interviewees had "air pollution" (No. 9), "critical water shortages in the Western Cape" (No. 20), or "intensive changes in temperature and weather" (No. 13) in mind. Additionally, they associated climate change with "environmental degradation" (No. 19), "the temperature could destroy like massive areas of natural habitat" (No. 5) or "sea life also facing extinction" (No. 5). Many interviewees once again mentioned the impact of human activity on climate change, for example, "the environment obviously changing not naturally but because of human influence" (No. 19), and "acceleration of change in the climate" due to "industrialization and human activity" (No. 4).

To further assess South Africans' attitudes towards climate change, interviewees were also asked how they felt about climate change. The more interviewees perceived climate change as a relevant problem, the more significant their concerns and fears were. Conversely, this meant that interviewees who felt that other social or personal issues were far more serious than climate change expressed little concern. This was evident in all neighborhoods. However, many interviewees maintained that they were highly concerned about the impacts of climate change. For example, they said that "climate change is all-encompassing" (No. 4), and "I suppose we [are] heading[,] worldwide[,] for a disaster" (No. 3). A 39-year old woman said: "I sometimes wonder if it's almost too late for us. If there is anything we can still do".

Only a few interviewees pointed out that they were not afraid of climate change or that they simply could not fight it. For example, a young woman said, "it doesn't bother me" (No. 17) and two other interviewees emphasized, "it's supposed to happen. [...] I think it could just be part of life" (No. 13) and "I feel it is something that is beyond my control" (No. 8). 


\section{Climate change-related media use and information sources across communities (RQ2)}

In addition to the perception of climate change in South African communities, we were interested in interviewees' use of information sources and media with regards to climate change. When asked, firstly, where they have heard or usually hear about climate change, there were no pronounced differences across the communities. The majority of interviewees indicated that they mostly come into contact with the issue via traditional news media as well as online media. They posited, for example, that "you read about it in the newspapers and hear it on TV and on the radio" (No. 20). Similarly, many interviewees indicated that schools were an important source for their knowledge about climate change, for example, that they heard about it in "high school in geography [where] they spoke about climate change" (No. 12). In addition, the topic of climate change has pervaded interpersonal communication, e.g. conversations with friends, where "[y]ou just hear about these things" (No. 20) as "people talk about it[.] It's everywhere" (No. 4).

Contrary to the question of whether interviewees had heard of climate change before, there were clear differences across communities in the specific sources of information and the intensity of their use to acquire information about climate change. Members of the urban community used a variety of sources to inform themselves about climate change and climate policies. Online and traditional news media were most frequently used, followed by personal conversations and information from NGOs. Political or religious authorities are rarely used for information about climate change. Media, NGOs, books and educational authorities are the main sources of information for interviewees from the urban low income community. The interviewees from Pniel (rural community) differ significantly from the other two communities. They primarily sought information from educational authorities, followed by news and online media.

Finally, we asked interviewees if they felt well informed about climate change. The majority of interviewees felt moderately well informed, but occasionally reported a lack of knowledge. They said, for instance, "I'd say above average" (No. 3) or "not as well as I should be" (No. 12).

However, a comparison of the three communities again reveals differences. For example, the urban community felt moderately to well informed about climate change, its causes and effects. A young man from Stellenbosch central said, for example, "I'm relatively well informed" (No. 19) and a 60-year-old man from Rozendal explained, "I could probably read a lot more, probably average" (No. 1). In contrast, interviewees from the urban low income community said they felt moderately to poorly informed, and the two interviewees from Pniel 
(rural community) said they did not feel well informed about climate change. For instance, a 72-year old man admitted, "not so very well, I try to keep myself informed about it" (No. 20).

\section{Discussion}

Perceptions of climate change are important, as they influence individual action as well as support for political measures and societal solutions. At the same time, perceptions of climate change have been shown to be intertwined with media presentations of the issue, as traditional and, more recently, online media have become important sources of climate change-related information for many.

Therefore, many scholars have analyzed climate change-related perceptions and use of media and other sources of information in recent years. But this scholarship mostly focuses on "Western", industrialized countries and is quantitative in nature, employing standardized methods that are limited in the detail of their description.

This study remedied some of these shortcomings: It presents a qualitative, interviewbased study of three communities in Stellenbosch, South Africa, comparing their subjective conceptions of climate change, their attitudes towards it, and their respective use of media and information sources. We found both similarities as well as differences across the communities (see Table 2). Regarding the subjective concepts of climate change, the communities varied in that sense that members of the highly educated urban community had a differentiated and diverse perception of the causes and consequences of climate change and of possible countermeasures. Interestingly, several interviewees of the urban low income community had never heard of climate change before. Even after being told the main causes and effects of climate change, they did not know what climate change was. In addition, members of this community, more than the other two communities, stressed the financial impact of climate change on their lives. It was also interesting that the moderately wealthy and educated rural community had a clear understanding of the causes and consequences of climate change and thought that global warming needed to be tackled, but they could not name possible countermeasures. Nevertheless, almost all interviewees agreed that climate change was real and anthropogenic in nature, and a clear majority believed that politics had to act and combat climate change.

Regarding attitudes towards climate change, there were only minor differences across the communities. The majority of interviewees stressed that they are concerned and anxious about the impacts of climate change and that they considered it as an important problem, although other problems in the country seemed more pressing. In particular, the majority of 
members of the communities perceive political corruption in South Africa as a major problem that needs to be addressed. However, while the urban community identified crime and education as South Africa's most important problems, people from the urban low income community were primarily concerned about poverty and unemployment.

Asking about South Africans' climate change-related media use and information sources showed that in all three communities, both new and traditional mass media are important information sources. While educational authorities in the urban low income and rural communities seem to have a major impact on people's knowledge, they are not important sources of information in the urban community. In the central districts of Stellenbosch, interpersonal exchange of information on climate change also played an important role. Overall, interviewees' answers to the question of how well informed they feel about climate change largely corresponds with the average educational level of the respective community and, mostly, also with their individual levels of education. While the urban community (high level of education) feels rather well informed, interviewees in the urban low income community (moderate level of education) experience a more pronounced lack of knowledge.

Table 2. Perceptions and climate change communication across South African communities

\begin{tabular}{|c|c|c|c|}
\hline & Urban & Urban low income & Rural \\
\hline \multicolumn{4}{|l|}{ Subjective concepts } \\
\hline Existence of climate change & Real phenomenon & $\begin{array}{l}\text { Real phenomenon, } \\
\text { but some had never } \\
\text { heard of climate } \\
\text { change }\end{array}$ & Real phenomenon \\
\hline Possible causes & $\begin{array}{l}\text { Highly } \\
\text { differentiated } \\
\text { reflection }\end{array}$ & $\begin{array}{l}\text { Less differentiated } \\
\text { reflection }\end{array}$ & $\begin{array}{l}\text { Less differentiated } \\
\text { reflection }\end{array}$ \\
\hline $\begin{array}{l}\text { Impacts and personal } \\
\text { affectedness }\end{array}$ & $\begin{array}{l}\text { Felt personally } \\
\text { affected by the } \\
\text { impacts of climate } \\
\text { change }\end{array}$ & $\begin{array}{l}\text { Felt personally } \\
\text { affected by the } \\
\text { impacts of climate } \\
\text { change } \\
\text { (highlighted the } \\
\text { impacts on animals) }\end{array}$ & $\begin{array}{l}\text { Felt personally } \\
\text { affected by the } \\
\text { impacts of climate } \\
\text { change }\end{array}$ \\
\hline Countermeasures & $\begin{array}{l}\text { Named different } \\
\text { countermeasures }\end{array}$ & $\begin{array}{l}\text { Named different } \\
\text { countermeasures }\end{array}$ & $\begin{array}{l}\text { Unable to identify } \\
\text { potential } \\
\text { countermeasures }\end{array}$ \\
\hline
\end{tabular}

\section{Attitudes towards climate change}

Important issue, Important issue, but but other other Important issue, but personal/societal personal/societal other personal/societal 


\begin{tabular}{llll} 
& $\begin{array}{l}\text { problems are } \\
\text { more relevant } \\
\text { (e.g., political } \\
\text { corruption) }\end{array}$ & $\begin{array}{l}\text { problems are more } \\
\text { relevant (e.g., } \\
\text { unemployment) }\end{array}$ & $\begin{array}{l}\text { problems are more } \\
\text { relevant (e.g., } \\
\text { education) }\end{array}$ \\
$\begin{array}{l}\text { Visible and } \\
\text { tangible causes } \\
\text { and impacts }\end{array}$ & $\begin{array}{l}\text { Visible and tangible } \\
\text { causes and impacts }\end{array}$ & $\begin{array}{l}\text { Visible and } \\
\text { tangible causes and } \\
\text { Feelings }\end{array}$ \\
$\begin{array}{l}\text { Fears and worries } \\
\text { depending on the } \\
\text { awareness of the } \\
\text { problem }\end{array}$ & $\begin{array}{l}\text { Fears and worries } \\
\text { depending on the } \\
\text { awareness of the } \\
\text { problem }\end{array}$ & $\begin{array}{l}\text { Fears and worries } \\
\text { depending on the } \\
\text { awareness of the } \\
\text { problem }\end{array}$ \\
\hline
\end{tabular}

Climate change-related media use and communication

Encounter with issue

Information sources

Subjective knowledge

Traditional news
and online media
and interpersonal
communication
Variety of
information
sources
Felt moderately to
well informed

Traditional news and
online media and
interpersonal
communication
Media, NGOs, books
and educational
authorities
Felt moderately to
poorly informed

Traditional news and online media and interpersonal communication Educational authorities, new and online media Felt not well informed

These findings are of academic and practical relevance. For scholars of climate changerelated perceptions and communication, they add an interesting, previously neglected case in South Africa. Our results show that some findings that have been developed in other countries of the Global South hold true for this country as well, such as the limited understanding of the human contribution to climate change (Wolf \& Moser, 2011) or the serious concern about climate change (Lorenzoni \& Pidgeon, 2006; Seager, 2008). On the other hand, South Africa also has instructive specifics: While the different communities share similar attitudes towards climate change and often perceive effects of climate change in their daily lives already, they differ widely in their perceptions of possible causes and effects of climate change as well as of potential countermeasures. The reasons for this divergence may lie in the communities' sociodemographic make-up, which in South Africa still divides neighboring communities.

In addition, our findings should enable communicators to understand South African communities better, and to address them in more satisfactory ways. For example, they could address different audiences more specifically by taking prior knowledge or living conditions into account, and by strengthening links between other relevant societal issues and climate change. Communication of information about climate change should align with people's life 
contexts (see also Burton et al., 2010). Information should furthermore be communicated in local contests and easily accessible. There is probably a need to increase public awareness of climate change in general (see also Neville, 2010).

While we believe that this study has merit, it also has limitations. It is a small study, conducted in a specific region and town of a generally highly diverse country. As a qualitative study whose strengths lies mostly in the close and illustrative description of case-specific characteristics, it analyses few and, potentially, specific cases. However, the results of this study mirror prior studies from South Africa (e.g., Burton et al., 2010) and other countries in the Global South quite well and, due to the qualitative research design, are able to offer unique social and cultural insights into climate change-related perception across South African communities. Nonetheless, more research on South Africa is needed, research that should also examine the influence of social categories such as gender or age on respondents' climate-related perceptions in more detail.

\section{Disclosure statement}

No potential conflict of interest was reported by the authors.

\section{Data availability statement}

Data will be made available upon request from the corresponding author. 


\section{References}

Abramson, P., \& Inglehart, R. (1995). Value Change in Global Perspective. Ann Arbor: University of Michigan Press.

Babugura, A. (2010). Gender and Climate change: South Africa Case Study. Retrieved from https://www.boell.de/sites/default/files/assets/boell.de/images/download_de/ecology/south _africa.pdf

Bakuwa, J. (2015). Public understanding of global climate change in Malawi: an investigation of factors influencing perceptions, attitudes and beliefs about global climate change. Stellenbosch: Stellenbosch University.

Ballantyne, R., \& Oelofse, C. (1999). Informal settlers' perceptions of environmental quality: A case study of the Mizamoyethu Community, South Africa. The Environmentalist, 19(3), 203-215.

Billett, S. (2010). Dividing climate change: global warming in the Indian mass media. Climatic Change, 99(1-2), 1-16.

Brechin, S. R., \& Bhandari, M. (2011). Perceptions of climate change worldwide. Wiley Interdisciplinary Reviews: Climate Change, 2(6), 871-885.

Brevini, B., \& Lewis, J. (2018). Climate Change and the Media. New York: Peter Lang. Brüggemann, M., \& Engesser, S. (2017). Beyond false balance: How interpretive journalism shapes media coverage of climate change. Global Environmental Change, 42, 58-67.

Bryan, E., Deressa, T. T., Gbetibouo, G. A., \& Ringler, C. (2009). Adaptation to climate change in Ethiopia and South Africa: options and contraints. Environmental Science \& Policy, 12(4), 413-426.

Burton, M., Cooke, S., Godfrey, A., Neville, L., Pauker, E., \& le Roux-Rutledge, E. (2010). Africa Talks Climate. The public understanding of climate change in ten countries. Executive Summary. BBC World Service Trust.

Carvalho, A. (2010). Media(ted)discourses and climate change: a focus on political subjectivity and (dis)engagement. Wiley Interdisciplinary Reviews: Climate Change, 1(2), $172-179$.

Crona, B., Wutich, A., Brewis, A., \& Gartin, M. (2013). Perceptions of climate change: Linking local and global perceptions through a cultural knowledge approach. Climatic Change, 119(2), 519-531.

Dados, N., \& Connell, R. (2012). The Global South. Contexts, 11(1), 12-13. 
DARA (2012). Climate Vulnerability Monitor: A Guide to the Cold Calculus of a Hot Planet. Retrieved from https://daraint.org/wp-content/uploads/2012/09/CVM2ndEdFrontMatter.pdf

Guenther, L., Weingart, P., \& Joubert, M. (2018). Bridging the gap - mapping science, health and technology coverage in South Africa. In M. W. Bauer, P. Pansegrau, \& R. Shukla (Eds.), The Cultural Authority of Science. Comparing across Europe, Asia, Africa and the Americas (pp. 122-136). Routledge.

Guenther, L., Weingart, P., \& Meyer, C. (2018). "Science is Everywhere, but No One Knows It": Assessing the Cultural Distance to Science of Rural South African Publics.

Environmental Communication, 12(8), 1046-1061.

HSRC (2007). Human Sciences Research Council. Annual Report 2007-2008.

IPCC (2007). Climate Change 2007: Synthesis Report.

IPCC (2014). Climate Change 2014: Synthesis Report.

IPCC (2018). Global Warming of $1.5^{\circ} \mathrm{C}$ : An IPCC Special Report.

Lee, T. M., Markowitz, E. M., Howe, P. d., Ko, C.-Y., \& Leiserowitz, A. (2015). Predictors of public climate change awareness and risk perception around the world. Nature Climate Change, 5(11), 1014-1020.

Leiserowitz, A. (2005). American risk perceptions: Is climate change dangerous? Risk Analysis: an Official Publication of the Society for Risk Analysis, 25(6), 1433-1442.

Leiserowitz, A. (2007). International Public Opinion, Perception, and Understanding of Global Climate Change: Human Development Report 2007/2008.

Leiserowitz, A., Maibach, E., \& Roser-Renouf, C. (2009). Global Warming's Six Americas 2009.

Lorenzoni, I., \& Pidgeon, N. F. (2006). Public Views on Climate Change: European and USA Perspectives. Climatic Change, 77(1-2), 73-95.

Mandleni, B., \& Anim, F.D.K. (2011). Perceptions of Cattle and Sheep Farmers on Climate Change and Adaptation in the Eastern Cape Province of South Africa. Journal of Human Ecology, 34(2), 107-112.

Maponya, P., Mpandeli, S., \& Oduniyi, S. (2013). Climate Change Awareness in Mpumalanga Province, South Africa. Journal of Agricultural Science, 5(10).

Mayring, P. (2015). Qualitative Content Analysis: Theoretical Background and Procedures. In A. Bikner-Ahsbahs, C. Knipping, \& N. Presmeg (Eds.), Advances in Mathematics Education. Approaches to qualitative research in mathematics education: Examples of methodology and methods (Vol. 23, pp. 365-380). Dordrecht: Springer. 
Metag, J., Füchslin, T., \& Schäfer, M. S. [Mike S.] (2017). Global warming's five Germanys: A typology of Germans' views on climate change and patterns of media use and information. Public Understanding of Science, 26(4), 434-451.

Midgley, G., Chapman, A., Hewitson, B. [B.], Johnston, P., de Wit, M., Ziervogel, G., . . van Wilgen, B. (2005). A status quo, vulnerability and adaptation assessment of the physical and socio-economic effects of climate change in the Western Cape. Report to the Western Cape Government, Cape Town, South Africa.

Moser, S. C. (2010). Communicating climate change: history, challenges, process and future directions. Wiley Interdisciplinary Reviews: Climate Change, 1(1), 31-53.

Murphy, P. D., \& Tinga, T. M. (2019). Communication for Development and Social Change and the Challenge of Climate Change. International Journal of Communication, 13, 12521270.

Neville, L. (2010). South Africa talks climate. BBC World Service Trust conducted research in South Africa to gauge public understanding of climate change.

Nisbet, M. C., Ho, S. S., Markowitz, E., O'Neill, S., Schäfer, M. S., \& Thaker, J. (2018). The Oxford Encyclopedia of Climate Change Communication.

O'Connor, R. E., Bard, R. J., \& Fisher, A. (1999). Risk Perceptions, General Environmental Beliefs, and Willingness to Address Climate Change. Risk Analysis, 19(3), 461-471.

Painter, J. (2014). Disaster Averted? Television Coverage of the 2013/14 IPCC's Climate Change Reports.

Przeworski, A., \& Teune, H. (1970). The logic of comparative social inquiry. Comparative studies in behavioral science. New York: Wiley.

Pugliese, A., \& Ray, J. (2011). Fewer Americans, Europeans View Global Warming as a Threat. Retrieved from https://news.gallup.com/poll/147203/fewer-americans-europeansview-global-warming-threat.aspx

Rao, S., \& Wasserman, H. (2007). Global media ethics revisited. Global Media and Communication, 3(1), 29-50. https://doi.org/10.1177/1742766507074358

Ray, J., \& Pugliese, A. (2011). Worldwide, Blame for Climate Change Falls on Humans: Americans among least likely to attribute to human causes. Retrieved from http://probeinternational.org/library/wp-content/uploads/2011/04/Gallup-Poll-WorldwideBlame-for-Climate-Change-Falls-on-Humans.pdf

Reynolds, T. W., Bostrom, A., Read, D., \& Morgan, M. G. (2010). Now what do people know about global climate change? Survey studies of educated laypeople. Risk Analysis: an Official Publication of the Society for Risk Analysis, 30(10), 1520-1538. 
Schäfer, M. S. (2015). Climate Change and the Media. In J. D. Wright (Ed.), International encyclopedia of the social \& behavioral sciences (2nd ed., pp. 853-859). Amsterdam: Elsevier.

Schäfer, M. S., \& Schlichting, I. (2014). Media Representations of Climate Change: A MetaAnalysis of the Research Field. Environmental Communication, 8(2), 142-160.

Schmidt, A., Ivanova, A., \& Schäfer, M. S. (2013). Media attention for climate change around the world: A comparative analysis of newspaper coverage in 27 countries. Global Environmental Change, 23(5), 1233-1248.

Seager, J. (2008). Blowing hot or cold? South African attitudes to climate change. Retrieved from http://www.hsrc.ac.za/uploads/pageContent/1607/Blowing\%20Hot\%20or\%20Cold.pdf

Selormey, E. E., Dome, M. Z., Osse, L., \& Logan, C. (2019). Change ahead: Experience and awareness of climate change in Africa. Afrobarometer Policy Paper No. 60.

Shanahan, M. (2009). Time to adapt? Media coverage of climate change in nonindustrialised countries. In T. Boyce \& J. Lewis (Eds.), Global crises and the media: Vol. 5. Climate change and the media (pp. 145-157). New York, NY: Lang.

Stamm, K. R., Clark, F., \& Eblacas, P. R. (2000). Mass communication and public understanding of environmental problems: the case of global warming. Public Understanding of Science, 9(3), 219-237.

Steynor, A., \& Pasquini, L. (2019). Informing climate services in Africa through climate change risk perceptions. Climate Services, 15.

Taddicken, M. (2013). Climate Change From the User's Perspective. Journal of Media Psychology, 25(1), 39-52.

Thomas, D. S. G., Twyman, C., Osbahr, H., \& Hewitson, B. (2007). Adaptation to climate change and variability: farmer responses to intra-seasonal precipitation trends in South Africa. Climatic Change, 83(3), 301-322.

Weber, E. U., \& Stern, P. C. (2011). Public understanding of climate change in the United States. The American Psychologist, 66(4), 315-328.

White, R. (2011). Climate change, uncertain futures and sociology of youth. Youth Studies Australia, 30(3), 13-19.

Whitmarsh, L. (2009). What's in a name? Commonalities and differences in public understanding of "climate change" and "global warming". Public Understanding of Science, 18(4), 401-420. 
Wolf, J., \& Moser, S. C. (2011). Individual understandings, perceptions, and engagement with climate change: insights from in-depth studies across the world. Wiley Interdisciplinary Reviews: Climate Change, 2(4), 547-569.

WRI (2014). WRI Around the World Annual Report 2014. 